\title{
Safety and tolerability of PD-1/PD-L1 inhibitors in elderly and frail patients with advanced malignancies
}

\author{
TOMOKI SAKAKIDA ${ }^{1}$, TAKESHI ISHIKAWA ${ }^{1,2}$, JUNJI UCHINO ${ }^{3}$, YUSUKE TABUCHI ${ }^{2,4}$, SATOSHI KOMORI ${ }^{5}$, \\ JUN ASAI $^{5}$, AKIHITO ARAI ${ }^{6}$, HIROAKI TSUNEZUKA ${ }^{7}$, TOSHIYUKI KOSUGA $^{8}$, HIROTAKA KONISHI ${ }^{8}$, \\ FUMIYA HONGO $^{9}$, MASAYOSHI INOUE ${ }^{7}$, SHIGERU HIRANO ${ }^{6}$, OSAMU UKIMURA ${ }^{9}$, \\ TETSUYA TAGUCHI ${ }^{2,10}$, KOICHI TAKAYAMA ${ }^{3}$ and YOSHITO ITOH ${ }^{1}$ \\ ${ }^{1}$ Department of Gastroenterology and Hepatology, Graduate School of Medical Science; ${ }^{2}$ Outpatient Oncology Unit, \\ University Hospital; ${ }^{3}$ Department of Pulmonary Medicine, Graduate School of Medical Science; \\ ${ }^{4}$ Department of Hospital Pharmacy; Departments of ${ }^{5}$ Dermatology and ${ }^{6}$ Otolaryngology-Head and Neck Surgery; \\ Divisions of ${ }^{7}$ Thoracic Surgery and ${ }^{8}$ Digestive Surgery, Department of Surgery; \\ ${ }^{9}$ Department of Urology; ${ }^{10}$ Division of Endocrine and Breast Surgery, Department of Surgery, \\ Graduate School of Medical Science, Kyoto Prefectural University of Medicine, Kamigyo-ku, Kyoto 602-8566, Japan
}

Received March 16, 2020; Accepted June 23, 2020

DOI: $10.3892 / 01.2020 .11875$

\begin{abstract}
The number of elderly patients with cancer has increased due to aging of the population. However, safety of programmed cell death-1 (PD-1) or programed cell death ligand 1 (PD-L1) inhibitors in elderly patients remains controversial, and limited information exists in frail patients. The present study retrospectively identified 197 patients treated with nivolumab, pembrolizumab or atezolizumab for unresectable advanced cancer between September 2014 and December 2018. Patients were divided into the elderly (age, $\geq 75$ years) and non-elderly (age, $<75$ years) groups. The detailed immune-related adverse events (irAE) profile and development of critical complications were evaluated. To assess tolerability, the proportion of patients who continued PD-1/PD-L1 inhibitor for $>6$ months was analyzed. In the two groups, a three-element frailty score, including performance status, Charlson Comorbidity Index and neutrophil-lymphocyte ratio, was estimated, and patients were divided into the low-, intermediate- and high-frailty subgroups. Safety and
\end{abstract}

Correspondence to: Dr Takeshi Ishikawa, Department of Gastroenterology and Hepatology, Graduate School of Medical Science, Kyoto Prefectural University of Medicine, 465 Kajiicho, Hirokoji Agaru, Kawaramachi Street, Kamigyo-ku, Kyoto 602-8566, Japan E-mail: iskw-t@koto.kpu-m.ac.jp

Abbreviations: ICI, immune checkpoint inhibitors; PD-1, programmed cell death protein-1; PD-L1, programmed cell death ligand 1; NSCLC, non- small cell lung cancer; MM, malignant melanoma; irAEs, immune-related adverse events; CTLA-4, cytotoxic T-lymphocyte associated protein-4; PS, performance status; CCI, Charlson Comorbidity Index; NLR, neutrophil-lymphocyte ratio

Key words: immune-related adverse events, programmed cell death 1 inhibitors, immune checkpoint inhibitors, frail, elderly, aging tolerability were evaluated using the aforementioned items. A total of 58 patients $(29.4 \%)$ were aged $\geq 75$ years. No significant difference was found in the development of irAEs, hospitalization and treatment discontinuation due to irAEs between the two groups. However, the occurrence of unexpected critical complications was significantly higher in the elderly group $(\mathrm{P}=0.03)$. Among the elderly patients with high frailty, more critical complications and fatal irAE (hepatitis) were observed. In this population, $33.3 \%$ were able to continue treatment for $>6$ months without disease progression. The present analysis based on real world data showed similar safety and tolerability of PD-1/PD-L1 inhibitors in elderly patients with advanced malignancies. However, the impact of irAE in elderly patients, especially those with frailty, was occasionally greater compared with that in younger and fit patients.

\section{Introduction}

As a result of population aging, the number of elderly patients with cancer is recently increasing, and of patients with cancer, $\sim 70 \%$ are aged $\geq 65$ years and $36 \%$ are aged 75 years in daily clinical practice (1). Elderly patients are frequently vulnerable and frail compared to younger patients due to comorbidities and geriatric problems, including physical or cognitive dysfunctions (2), and non-elderly patients may also have frailty with malnutrition or low performance status (PS) due to severe advanced malignancies. In these situations, conventional cancer treatments are often intolerable and have a particularly high risk of adverse events (3).

Immune checkpoint inhibitors (ICIs), especially those targeting the programmed cell death-1 (PD-1) and programmed cell death ligand 1 (PD-L1), which have improved outcomes for various advanced cancers, including non-small cell lung cancer (NSCLC), malignant melanoma (MM), renal cell carcinoma, urothelial cancer, head and neck cancer and gastric cancer (4-9), are generally considered to be more tolerable 
than conventional chemotherapy and clinical indications for immunotherapy continue to increase $(4,10)$. These drugs may provide an opportunity for treatment of elderly or frail patients who cannot tolerate toxic chemotherapy or invasive treatment.

The age-related decline in the immune system, so called 'immunosenescence' has been recently reported in preclinical studies $(11,12)$. $\mathrm{T}$ cells, the primary effectors of antitumor response, undergo significant changes with age. The naïve $\mathrm{CD}^{+} \mathrm{T}$ cells decline with age in part due to thymic involution and contraction of lymphopoietic stem cells (13), and decreased expression of CD28 on the surface of CD8 ${ }^{+} \mathrm{T}$ cells leads to decreased immune activation (14-16). While these numeric and functional defects in $\mathrm{T}$ cells have been characterized gradually, the potential impact of aging on efficacy and tolerability of immunotherapy in clinical practice remains unclear. Elderly patients has been underrepresented in clinical trials; moreover, those who were included had relatively good PS and function reserve capacities, which may not reflect the real-world population (17). The real-world clinical practice data in treating more vulnerable or frail patients with ICIs are severely insufficient, and identifying the safety and efficacy of ICIs in this population would be profitable.

Hence, based on a real-world cohort, we designed a two-part study: i) We evaluated the safety and tolerability of PD-1/PD-L1 monotherapy in elderly patients with advanced malignancies. ii) Using indirect markers of frailty including Eastern Cooperative Oncology Group (ECOG)-PS, Charlson Comorbidity Index (CCI), and neutrophil-lymphocyte ratio (NLR), we estimated whether vulnerable and frail patients in the elderly and non-elderly groups were associated with higher risk of immune-related adverse events (irAEs) or complications.

\section{Materials and methods}

Patient population and data collection. We performed a retrospective review of electronic medical records of 197 patients who received nivolumab, pembrolizumab or atezolizumab as monotherapy for metastatic or unresectable advanced cancers from September 2014 to December 2018 at Kyoto Prefecture University of Medicine. These patients' data were continuously followed until the data lock on July 31, 2019. None of the patients had a history of pretreatment with other ICIs, such as ipilimumab, which is an anti-cytotoxic T-lymphocyte associated protein- 4 antibody. This study was approved by the Medical Ethics Review Committee of the Kyoto Prefectural University of Medicine. Given the retrospective nature of this work, informed consent was waived for the participants included in the study in accordance with the standards of the Kyoto Prefectural University of Medicine Institutional Medical Ethics Review Committee.

All enrolled patients received PD-1/PD-L1 inhibitor intravenously, according to a schedule of $3 \mathrm{mg} / \mathrm{kg}$ or $240 \mathrm{mg}$ every 2 weeks for nivolumab, $2 \mathrm{mg} / \mathrm{kg}$ or $200 \mathrm{mg}$ every 3 weeks for pembrolizumab, and 1,200 mg every 3 weeks for atezolizumab. The treatment was provided until disease progression or unacceptable toxicity or complication was noted.

We collected information on patients' age, sex, body mass index (BMI), tumor type, ECOG-PS (18), laboratory values, prior cancer treatments and comorbidities to calculate $\mathrm{CCI}$ scores at the time of induction of PD-1/PD-L1 inhibitors (19).
NLR, an inflammatory marker that is reported to be associated with frailty and nutritional status $(20,21)$, and the prognostic nutritional index (PNI), which is also a nutritional marker used in various cancer types, was also calculated using laboratory findings (22-25). Additionally, we assessed the development, severity and clinical course of all irAEs, namely, thyroid dysfunction, cutaneous disorders, interstitial pneumonitis, colitis, adrenal insufficiency, hepatitis, diabetes, and encephalitis. Hepatitis was defined as liver dysfunction with compatible pathological findings from liver biopsy or determined by a hepatologist. The severity of irAE was graded according to the CTCAE 4.0 criteria.

Furthermore, the duration of PD-1/PD-L1 treatment of each patient was retrieved from the medical records. This was defined as the time from the start of PD-1/PD-L1 treatment to the date of documented disease progression or any events that led to treatment discontinuation. Evaluation of clinical responses was based on the laboratory findings and the Response Evaluation Criteria in Solid Tumors version 1.1. The patients were evaluated after the first 2-3 cycles and underwent computed tomography or magnetic resonance imaging every 2-3 months according to the attending physician.

Assessment. Initially, all 197 patients were divided into two groups based on their age: Elderly group (age $\geq 75$ years) and non-elderly group (age $<75$ years). In the assessment of safety, development and severity of each irAE, hospitalization and discontinuation of PD-1/PD-L1 inhibitor treatment due to irAEs, requirement of corticosteroids or immunosuppressants for irAEs, and development of unexpected critical complications were evaluated. Moreover, the proportion of patients who continued PD-1/PD-L1 inhibitor treatment for $>6$ months was analyzed for verification of tolerability among the two groups.

Since no formal geriatric assessments were performed, we used indirect markers to assess frailty. Namely, we constructed a three-element frailty scoring system, including ECOG-PS, CCI and NLR. These indirect markers were evaluated at the time of first administration of PD-1/PD-L1 inhibitors. PS $\geq 2$, CCI score $\geq 3$ and NLR $\geq 4$ were each given one point and the frailty score (FS) was calculated by adding the points of individual factors, as shown in Table I. We defined patients with $\mathrm{FS}=0$ as having low, $\mathrm{FS}=1$ as intermediate and $\mathrm{FS}=2$ or 3 as high frailty. Based on this score, we respectively divided the elderly and non-elderly patients into low-, intermediate-, and high-frailty subgroups and evaluated the safety and tolerability of PD-1/PD-L1 inhibitor treatment as mentioned above.

Statistical analysis. Continuous variables were presented as median with range according to their distribution. Student's t-test and Mann-Whitney U test were used to compare continuous variables between the elderly and non-elderly groups. The Chi-square test or Fisher's exact test was used to compare categorical variables. A Bonferroni adjustment was used for multiple comparisons. All statistical tests were two-sided, and a P-value $<0.05$ indicated statistical significance. All statistical analyses were performed using JMP ${ }^{\circledR} 13$ (SAS Institute Inc.).

\section{Results}

Baseline characteristics. This study group of 197 patients consisted of 77 patients with NSCLC, 32 with MM, 29 with 


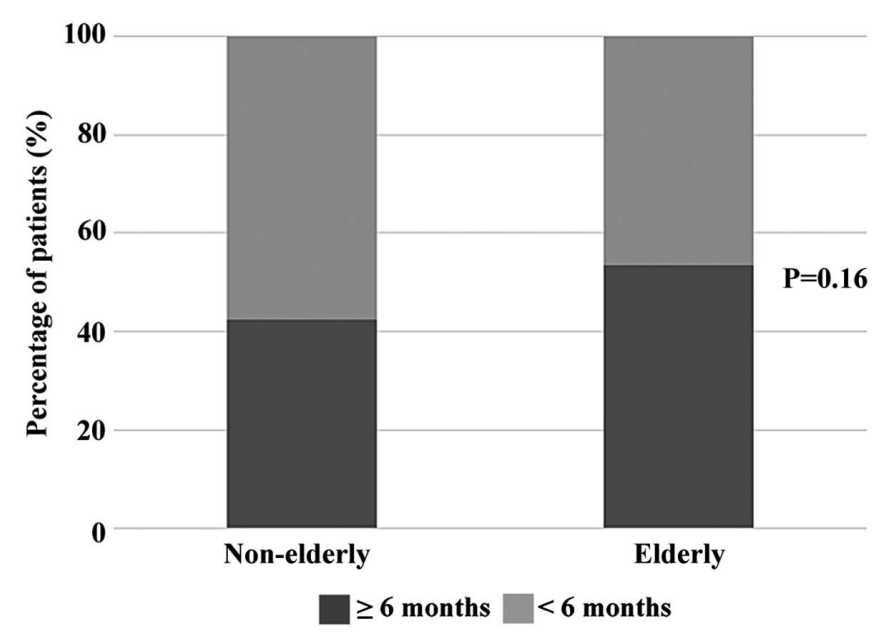

Figure 1. Treatment period in the non-elderly and elderly groups. A total of 59 patients $(42.5 \%)$ in the non-elderly group and 31 patients $(53.5 \%)$ in the elderly group were able to continue programmed cell death protein-1/programmed cell death ligand 1 inhibitor treatment for $>6$ months. The $\chi^{2}$ test was performed for comparison.

head and neck cancer, 27 with renal cell carcinoma, 23 with gastric cancer, and 9 with urothelial cancer. Of these patients, 146 received nivolumab, 42 received pembrolizumab and 9 received atezolizumab. At the time of analysis, the median follow-up duration was 43 weeks (range 2-254 weeks). There were 58 patients $(29.4 \%)$ aged $\geq 75$ years and 139 patients $(70.6 \%)$ aged $<75$ years, which constituted the elderly and non-elderly groups, respectively. The baseline clinical characteristics of the patients in the two groups are shown in Table II. The average age in the non-elderly and elderly groups was 62.5 and 79.4 years $(\mathrm{P}<0.001)$, respectively. There were no significant differences in sex, BMI, follow-up duration, type of PD-1/PD-L1 inhibitor administered, prior therapy lines, PS, NLR and PNI. A certain deviation in tumor type was observed, and the elderly group showed fewer prior therapy lines and higher CCI scores, although these did not reach statistical significance. In addition, 2 out of 7 patients with preexisting autoimmune disease were in use of corticosteroids or immunosuppressants at baseline; namely, a 70 years old man with dermatomyositis used corticosteroids and a 79 years old woman with rheumatoid arthritis used corticosteroids and immunosuppressants.

Profiles of irAEs in the elderly and non-elderly groups. The profiles of irAEs in the elderly and non-elderly groups are shown in Table III. Moreover, 52 patients (37.4\%) in the non-elderly group and 28 patients $(48.3 \%)$ in the elderly group developed any irAEs of any grade, which showed a slight tendency of more irAEs in elderly patients, although the difference was not statistically significant. Moreover, the analysis of irAEs showed no significant difference in the development of cutaneous disorders, thyroid dysfunction, interstitial pneumonitis, adrenal insufficiency, hepatitis, and diabetes. The severity of irAEs and clinical outcomes related to irAEs are shown in Table IV. Grade 3-5 irAEs developed equally in the non-elderly and elderly groups $[12$ patients $(8.6 \%)$ in the non-elderly group and $5(8.6 \%)$ in the elderly group], although one elderly patient with renal cell carcinoma developed grade 5
Table I. Frailty scoring system.

\begin{tabular}{lcc}
\hline Marker & Value & Score \\
\hline Performance Status & $0-1$ & 0 \\
& $\geq 2$ & 1 \\
Charlson Comorbidity Index & $0-2$ & 0 \\
Neutrophil-Lymphocyte Ratio & $\geq 3$ & 1 \\
& $<4$ & 0 \\
Total & $\geq 4$ & 1 \\
& Low & 0 \\
& Intermediate & 1 \\
& High & 2,3
\end{tabular}

hepatitis (fulminant hepatitis), which showed resistance to pulse steroid therapy and died after the 4th cycle of nivolumab. Although the following data did not show statistical significance, hospitalization due to irAEs and use of corticosteroids or immunosuppressants for irAEs were slightly higher in the elderly patients, and PD-1/PD-L1 inhibitor treatment was more easily discontinued in the elderly group than in the non-elderly group [9 patients $(15.5 \%)$ vs. 13 patients $(9.4 \%)(\mathrm{P}=0.21)$ ]. Furthermore, unexpected critical complications developed more frequently in the elderly patients $(\mathrm{P}=0.03)$, including each patient with acute exacerbation of chronic heart failure, cerebral hemorrhage, femoral neck fracture due to fall and sudden unexplained death.

When we analyzed the treatment duration among the two groups, 59 patients $(42.5 \%)$ in the non-elderly group and 31 patients $(53.5 \%)$ in the elderly group were able to continue PD-1/PD-L1 inhibitor treatment for $>6$ months (Fig. 1). In addition, patients who had longer treatment duration showed tendency to develop more irAEs in the two groups, especially in the non-elderly patients [ 29 patients $(49.2 \%)$ with treatment period $\geq 6$ months and 23 patients $(28.8 \%)$ ] with treatment period $<6$ months, $\mathrm{P}=0.01$, data not shown). According to these results, PD-1/PD-L1 inhibitors seemed to have comparable tolerability in elderly patients.

Frailty scores. In the non-elderly group, 75 patients $(54.0 \%)$ with $\mathrm{FS}=0,51$ patients $(36.7 \%)$ with $\mathrm{FS}=1$ and 13 patients $(9.3 \%)$ with $\mathrm{FS}=2$ or 3 were defined as patients with low, intermediate and high frailty, respectively. In the elderly group, 30 patients $(51.7 \%)$ with $\mathrm{FS}=0,16$ patients $(27.6 \%)$ with $\mathrm{FS}=1$, and 12 patients $(20.7 \%)$ with $\mathrm{FS}=2$ or 3 were defined as patients with low, intermediate and high frailty, respectively. The proportion of patients with high frailty was considerably greater in the elderly group and close to significance $(\mathrm{P}=0.08)$.

Development of irAEs and clinical outcomes in patients with low, intermediate, and high frailty. The development of irAEs and unexpected critical complications in the three frailty subgroups of the non-elderly and elderly patients are demonstrated in Tables V and VI. In the non-elderly patients, 35 patients $(46.7 \%)$ with low frailty, 15 patients $(29.4 \%)$ with intermediate frailty and 2 patients $(15.4 \%)$ with high frailty developed any irAEs of any grade, which showed a tendency 
Table II. Baseline characteristics of non-elderly $(n=139)$ and elderly $(n=58)$ patients.

\begin{tabular}{|c|c|c|c|}
\hline Characteristics & Non-elderly (age $<75$ years) & Elderly (age $\geq 75$ years) & P-value \\
\hline Age, years & 62.5 & 79.4 & $<0.01$ \\
\hline Sex, n (male/female) & $93 / 46$ & $39 / 19$ & 0.96 \\
\hline $\mathrm{PS}, \mathrm{n}$ & & & 0.72 \\
\hline 0 & 78 & 32 & \\
\hline 1 & 45 & 17 & \\
\hline$\geq 2$ & 16 & 9 & \\
\hline Median follow-up period, weeks (range) & $40(2-254)$ & $52(8-170)$ & 0.12 \\
\hline Tumor type, $\mathrm{n}$ & & & 0.08 \\
\hline NSCLC & 56 & 21 & \\
\hline MM & 18 & 14 & \\
\hline Head and neck & 25 & 4 & \\
\hline $\mathrm{RCC}$ & 20 & 7 & \\
\hline Gastric & 16 & 7 & \\
\hline Urothelial & 4 & 5 & \\
\hline Treatment, $\mathrm{n}$ & & & 0.84 \\
\hline Nivolumab & 106 & 40 & \\
\hline Pembrolizumab & 26 & 16 & \\
\hline Atezolizumab & 7 & 2 & \\
\hline Prior therapy lines, $n(\leq 1 / \geq 2)$ & $68 / 71$ & $36 / 22$ & 0.09 \\
\hline $\mathrm{CCI}, \mathrm{n}$ & & & 0.09 \\
\hline 0 & 74 & 25 & \\
\hline 1,2 & 55 & 23 & \\
\hline$\geq 3$ & 10 & 10 & \\
\hline BMI & 21.2 & 20.9 & 0.58 \\
\hline NLR & 4.1 & 3.8 & 0.50 \\
\hline PNI & 43.2 & 43.6 & 0.71 \\
\hline Preexisting autoimmune disease, $\mathrm{n}$ & 4 & 3 & 0.43 \\
\hline
\end{tabular}

PS, performance status; NSCLC, non-small cell lung carcinoma; MM, malignant melanoma; RCC, renal cell carcinoma; CCI, Charlson's comorbidity index; BMI, body mass index; NLR, neutrophil lymphocyte ratio; PNI, prognostic nutritional index.

of lower development of irAEs in patients with high frailty $(\mathrm{P}=0.09)$. No significant difference was shown in the development of severe irAEs among the three groups. One patient with low frailty had exacerbation of the preexisting dermatomyositis 17 days after initiation of atezolizumab.

In the elderly patients, 17 patients $(56.7 \%)$ with low frailty, 7 patients $(43.8 \%)$ with intermediate frailty, and 4 patients $(33.3 \%)$ with high frailty developed any irAEs of any grade $(\mathrm{P}=0.36)$. There was also no significant difference in the development of grade 3-5 irAEs among the three subgroups. However, it should be noted that two patients with high frailty developed critical complications, including a case of sudden death.

Tables VII and VIII show the clinical outcomes of all patients (12 patients in the non-elderly group, 5 in the elderly group) who developed grade 3-5 irAEs. All non-elderly patients recovered from severe irAEs, including one patient with low and one patient with intermediate frailty restarting the same PD-1/PD-L1 inhibitor. In contrast, one elderly patient with high frailty died of fulminant hepatitis as mentioned above, and no other patient resumed ICI treatment afterward.

When we focused on the treatment duration of PD-1/PD-L1 inhibitor among the three frailty subgroups, patients with low frailty showed a tendency to continue treatment for $>6$ months in both non-elderly and elderly population (Figs. 2 and 3). Nevertheless, $33.3 \%$ of patients with high frailty aged $\geq 75$ years were able to continue PD-1/PD-L1 inhibitor treatment for $>6$ months, suggesting a certain level of efficacy and tolerability of these drugs in this population.

\section{Discussion}

In this study, we described the safety and tolerability of PD-1 inhibitors in elderly and frail patients with advanced malignancies. To the best of our knowledge, this is the first study to evaluate the correlation between indirect frailty markers and clinical outcomes in patients with advanced cancer treated by PD-1/PD-L1 inhibitors. 
Table III. Development of irAEs among the non-elderly $(n=139)$ and elderly $(n=58)$ groups.

\begin{tabular}{lccc}
\hline irAEs & Non-elderly $($ age $<75$ years $), n(\%)$ & Elderly $($ age $\geq 75$ years $), \mathrm{n}(\%)$ & P-value \\
\hline Total of irAEs & $52(37.4)$ & $28(48.3)$ & 0.16 \\
Thyroid dysfunction & $18(13.1)$ & $12(20.7)$ & 0.18 \\
Cutaneous disorders & $25(18.0)$ & $12(20.7)$ & 0.66 \\
Interstitial pneumonitis & $10(7.2)$ & $5(8.6)$ & 0.73 \\
Colitis & $6(4.3)$ & $2(3.5)$ & 0.78 \\
Adrenal insufficiency & $5(3.6)$ & $1(3.5)$ & 0.96 \\
Hepatits & $3(2.1)$ & $1(1.7)$ & 0.84 \\
Diabetes & $2(1.4)$ & 0.70
\end{tabular}

irAEs, immune related adverse events.

Table IV. Severity of irAEs and clinical outcomes related to irAEs in the non-elderly $(n=139)$ and elderly $(n=58)$ patients.

\begin{tabular}{|c|c|c|c|}
\hline Variables & Non-elderly (age <75 years), n (\%) & Elderly (age $\geq 75$ years), n (\%) & P-value \\
\hline Total of irAEs & $52(37.4)$ & $28(48.3)$ & 0.16 \\
\hline \multirow[t]{2}{*}{ Grade 3-5 irAEs } & $12(8.6)$ & $5(8.6)$ & 0.99 \\
\hline & Gr3: N=9, Gr4: N=3 & Gr3: N=2, Gr4: N=2, Gr5: N=1 & \\
\hline Hospitalization due to irAE & $12(8.6 \%)$ & $7(12.1 \%)$ & 0.46 \\
\hline Use of corticosteroids or & & & \\
\hline immunosuppressants for irAE & $17(12.2)$ & $8(13.8)$ & 0.76 \\
\hline Treatment discontinuation due to irAE & $13(9.4)$ & $9(15.5)$ & 0.21 \\
\hline Unexpected critical complications & $1(0.7)^{\mathrm{a}}$ & $4(6.9)^{b}$ & 0.03 \\
\hline
\end{tabular}

${ }^{a}$ Worsening of preexisting dermatomyositis $(n=1)$; ${ }^{b}$ Exacerbation of chornic heart failure $(n=1)$, cerebral hemorrhage $(n=1)$, femoral neck fracture $(n=1)$, sudden unexplained death $(n=1)$. irAEs, immune related adverse events; Gr, grade.

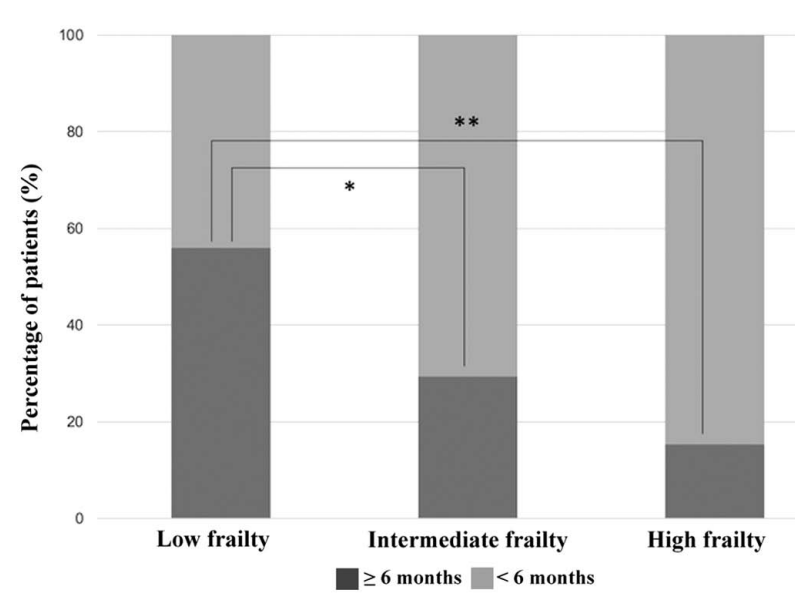

Figure 2. Treatment period in the three frailty subgroups of patients aged $<75$ years. A total of 42 patients (56.0\%), 15 patients (29.4\%) and 2 patients $(15.4 \%)$ in the low-, intermediate- and high-frailty subgroups, respectively, were able to continue programmed cell death protein-1/programmed cell death ligand 1 inhibitor treatment for $>6$ months. The proportion was significantly greater in the low-frailty group than the other groups. Fisher's exact test was used and Bonferroni adjustment was used for multiple comparisons. ${ }^{*} \mathrm{P}<0.05 ;{ }^{* *} \mathrm{P}<0.01$.

Our data showed that elderly patients developed slightly more irAEs of any grade than non-elderly patients, although this was not statistically significant. In detail, no significant difference

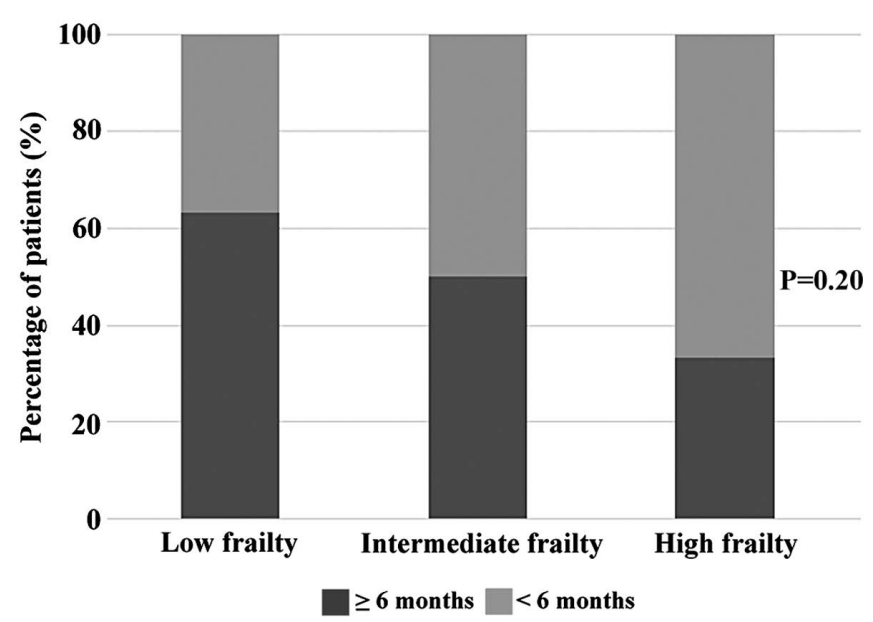

Figure 3. Treatment period in the three frailty subgroups of patients aged $\geq 75$ years. A total of 19 patients $(63.3 \%), 8$ patients $(50.0 \%)$ and 4 patients (33.3\%) in the low-, intermediate- and high-frailty subgroups, respectively, were able to continue programmed cell death protein-1/programmed cell death ligand 1 inhibitor treatment for $>6$ months. There was no significant difference among the three subgroups $(\mathrm{P}=0.20)$. Fisher's exact test was used and Bonferroni adjustment was used for multiple comparisons.

was found in the development of cutaneous disorders, thyroid dysfunction, interstitial pneumonitis, adrenal insufficiency, 
Table V. Development of irAEs and unexpected critical complications among the three subgroups of frailty (age $<75$ years).

\begin{tabular}{lcccr}
\hline Variables & $\begin{array}{c}\text { Low frailty } \\
(\mathrm{FS}=0)(\mathrm{n}=75), \mathrm{n}(\%)\end{array}$ & $\begin{array}{c}\text { Intermediate frailty } \\
(\mathrm{FS}=1)(\mathrm{n}=51), \mathrm{n}(\%)\end{array}$ & $\begin{array}{c}\text { High frailty } \\
(\mathrm{FS}=2,3)(\mathrm{n}=13), \mathrm{n}(\%)\end{array}$ & P-value \\
\hline Total of irAEs & $35(46.7)$ & $15(29.4)$ & $2(15.4)$ & 0.09 \\
Grade 3-5 irAEs & $5(6.7)$ & $5(9.8)$ & $2(15.4)$ & 0.55 \\
Unexpected critical & Worsening of preexisting & None & None & \\
complications & dermatomyositis $(\mathrm{n}=1)$ & & & \\
\hline
\end{tabular}

irAEs, immune related adverse events; FS, frailty score.

Table VI. Development of irAEs and unexpected critical complications among the three subgroups of frailty (age $\geq 75$ years).

\begin{tabular}{lccc}
\hline Variables & $\begin{array}{c}\text { Low frailty }(\mathrm{FS}=0) \\
(\mathrm{n}=30), \mathrm{n}(\%)\end{array}$ & $\begin{array}{c}\text { Intermediate frailty } \\
(\mathrm{FS}=1)(\mathrm{n}=16), \mathrm{n}(\%)\end{array}$ & $\begin{array}{c}\text { High frailty } \\
(\mathrm{FS}=2,3)(\mathrm{n}=12), \mathrm{n}(\%)\end{array}$ \\
\hline $\begin{array}{l}\text { Total of irAEs } \\
\text { Grade 3-5 irAEs }\end{array}$ & $17(56.7)$ & $7(43.8)$ & $4(33.3)$ \\
$\begin{array}{l}\text { Unexpected critical } \\
\text { complications }\end{array}$ & $2(6.7)$ & $2(12.5)$ & $1(8.3)$ \\
& $\begin{array}{l}\text { Cerebral hemorrhage }(\mathrm{n}=1), \\
\text { femoral neck fracture }(\mathrm{n}=1)\end{array}$ & None & $\begin{array}{l}\text { Exacerbation of chornic } \\
\text { heart failure (n=1),sudden } \\
\text { unexplained death }(\mathrm{n}=1)\end{array}$ \\
\hline
\end{tabular}

irAEs, immune related adverse events, FS, Frailty score.

hepatitis, and diabetes. Moreover, the development of severe irAEs was similar between the non-elderly and elderly patients. However, hospitalization or treatment discontinuation due to irAEs and use of corticosteroids or immunosuppressants were more frequent in the elderly group. Additionally, unexpected critical complications developed more often in this group, including a case of acute exacerbation of chronic heart failure, cerebral hemorrhage and sudden death.

When we assessed frailty using indirect markers such as PS, CCI and NLR, the incidence of severe irAEs was not associated with the frailty levels in both non-elderly and elderly groups. In non-elderly patients, all recovered with proper treatment and each case with low/intermediate frailty were able to restart the same PD-1 inhibitor. On the contrary, none of the patients were able to restart PD-1 treatment, and grade 5 hepatitis and fatal complications were observed in the high-frailty subgroup. This supports the idea that assessment of frailty is especially important in elderly patients.

In previous clinical trials, no major increase in the incidence of irAEs was noted in this population (26-28). However, only relatively fit patients were enrolled and patients with reduced functional reserve or age-related comorbidities were excluded in these trials and therefore not representative of the 'real-world' population. In limited observational studies based on more general population of patients, contradictory results are reported. Sattar et al (29) and Leroy et al (30) showed a trend of higher incidence of irAEs in elderly patients. Muchnik et al (31) reported that a larger proportion of elderly patients were hospitalized and required corticosteroids and treatment discontinuation. Although not statistically significant, our data also showed a trend to increased irAEs of any grade with more frequent hospitalization, need of immune-modulating medication and treatment discontinuation in elderly patients. Meanwhile, our results also showed that the proportion of patients who were able to continue PD-1/PD-L1 inhibitor treatment for $>6$ months was slightly larger in the elderly patients. This suggests that PD-1/PD-L1 inhibitors may have comparable tolerability and provide similar levels of benefit to elderly patients. These ambivalent findings were found retrospectively with small sample size, although it implies further investigation of the application of ICIs in elderly patients.

Patients with advanced malignancies have an increased risk of frailty due to cancer cachexia or tumor-related disabilities, and more than half of elderly patients are vulnerable or frail (32). Selecting frail patients using geriatric assessment can help personalize treatment decisions, which leads to less treatment-related adverse events and mortality (3). However, the best geriatric assessment tool to evaluate frailty has still not reached consensus and consequently not widely used in daily clinical practice (2). ICI treatment is generally considered to be more tolerable than chemotherapy, although there are still concerns about the greater impact of irAEs in frail patients than in fit patients due to comorbidities and reduced functional reserve. From the abovementioned background, only a few studies have described the correlation between frailty and safety of immunotherapy. Welaya et al (33) did not find any relationships between impairment in geriatric assessment domains and complications but showed that patients with impairments of instrumental activities of daily living had shorter treatment duration. Archibald et al (34) used indirect frailty markers reporting that frail elderly patients had similar response rates and treatment toxicity compared to fit patients. 
Table VII. Clinical features of the non-elderly patients with severe irAEs.

\begin{tabular}{|c|c|c|c|c|c|c|c|c|c|}
\hline Case & $\begin{array}{l}\text { Age, } \\
\text { years }\end{array}$ & Sex & $\begin{array}{l}\text { Tumor } \\
\text { type }\end{array}$ & Treatment & Frailty & irAE & Grade & $\begin{array}{l}\text { Remission } \\
\text { of irAE }\end{array}$ & $\begin{array}{c}\text { Restart of } \\
\text { PD-1/PD-L1 } \\
\text { treatment }\end{array}$ \\
\hline 1 & 60 & M & $\mathrm{RCC}$ & Nivolumab & Low & Diabetes & $\begin{array}{l}4 \text { (diabetic } \\
\text { ketoacidosis) }\end{array}$ & Yes & Yes \\
\hline 2 & 67 & $\mathrm{~F}$ & NSCLC & Nivolumab & Low & Diabetes & $\begin{array}{l}4 \text { (diabetic } \\
\text { ketoacidosis) }\end{array}$ & Yes & No \\
\hline 3 & 71 & M & Urothelial & Pembrolizumab & Low & Colitis & 3 & Yes & No \\
\hline 4 & 68 & M & $\mathrm{MM}$ & Nivolumab & Low & $\begin{array}{l}\text { Aderenal } \\
\text { insufficienecy }\end{array}$ & 3 & Yes & No \\
\hline 5 & 70 & $\mathrm{~F}$ & NSCLC & Nivolumab & Low & $\begin{array}{l}\text { Interstitial } \\
\text { pneumonitis }\end{array}$ & 3 & Yes & No \\
\hline 6 & 74 & $\mathrm{~F}$ & NSCLC & Nivolumab & Intermediate & Hepatitis & 4 & Yes & No \\
\hline 7 & 73 & M & NSCLC & Pembrolizumab & Intermediate & $\begin{array}{l}\text { interstitial } \\
\text { pneumonitis }\end{array}$ & 3 & Yes & No \\
\hline 8 & 71 & M & NSCLC & Atezolizumab & Intermediate & Encephatitis & 3 & Yes & No \\
\hline 9 & 63 & M & NSCLC & Nivolumab & Intermediate & $\begin{array}{l}\text { Interstitial } \\
\text { pneumonitis }\end{array}$ & 3 & Yes & No \\
\hline 10 & 60 & M & $\begin{array}{l}\text { Head and } \\
\text { neck }\end{array}$ & Nivolumab & Intermediate & Hepatitis & 3 & Yes & Yes \\
\hline 11 & 44 & M & Gastric & Nivolumab & High & $\begin{array}{l}\text { Interstitial } \\
\text { pneumonitis }\end{array}$ & 3 & Yes & No \\
\hline 12 & 73 & M & NSCLC & Pembrolizumab & High & $\begin{array}{l}\text { Aderenal } \\
\text { insufficinecy }\end{array}$ & 3 & Yes & No \\
\hline
\end{tabular}

irAEs, immune-related adverse events; NSCLC, non-small cell lung carcinoma; MM, malignant melanoma; RCC, renal cell carcinoma.

Table VIII. Clinical features of the elderly patients with severe irAEs.

\begin{tabular}{|c|c|c|c|c|c|c|c|c|c|}
\hline Case & $\begin{array}{l}\text { Age, } \\
\text { years }\end{array}$ & Sex & $\begin{array}{l}\text { Tumor } \\
\text { type }\end{array}$ & Treatment & Frailty & irAE & Grade & $\begin{array}{l}\text { Remission } \\
\text { of irAE }\end{array}$ & $\begin{array}{c}\text { Restart of } \\
\text { PD-1/PD-L1 } \\
\text { treatment }\end{array}$ \\
\hline 1 & 78 & M & NSCLC & Pembrolizumab & Low & $\begin{array}{l}\text { Aderenal } \\
\text { insufficienecy }\end{array}$ & 3 & Yes & No \\
\hline 2 & 75 & M & $\mathrm{RCC}$ & Nivolumab & Low & $\begin{array}{l}\text { Aderenal } \\
\text { insufficienecy }\end{array}$ & 3 & Yes & No \\
\hline 3 & 84 & $\mathrm{~F}$ & MM & Nivolumab & Intermediate & $\begin{array}{l}\text { Cutaneous } \\
\text { disorder }\end{array}$ & $\begin{array}{l}4 \text { (Stevens-Johnson } \\
\text { syndrome) }\end{array}$ & Yes & No \\
\hline 4 & 77 & $\mathrm{~F}$ & MM & Nivolumab & Intermediate & Diabetes & $\begin{array}{l}4 \text { (diabetic } \\
\text { ketoacidosis) }\end{array}$ & Yes & No \\
\hline 5 & 80 & $\mathrm{~F}$ & $\mathrm{RCC}$ & Nivolumab & High & Hepatitis & $\begin{array}{l}5 \text { (fulminant } \\
\text { hepatits) }\end{array}$ & No (died) & No \\
\hline
\end{tabular}

irAEs, immune-related adverse events; NSCLC, non-small cell lung carcinoma; MM, malignant melanoma; RCC, renal cell carcinoma.

We also used indirect markers such as ECOG-PS, CCI and NLR, which have been reported to correlate with frailty $(20,35,36)$, and created an original scoring system showing marginally difference between elderly and non-elderly patients. Indeed, this system is not sufficient, although provided a certain indication of frailty in cancer patients. Further evaluation of frailty markers, classification systems and geriatric assessment tools are urgently warranted in this field.

In this study, we did not find a correlation between the development of grade 3-5 irAEs and frailty levels but warned that fatal irAEs and complications may develop more frequently in frail elderly patients. This may be a result of reduced functional 
reserve or interaction of adverse events and comorbidities. Although some recent studies have reported the safety and efficacy of retreatment with ICIs after irAEs, contradictory reports exist and no consensus has been reached yet (37-39). Therefore, restarting ICIs after irAEs may be too challenging for these patients. Regardless of age, the treatment duration was shorter in frail patients. Perhaps, this was because frailty was defined based on PS and NLR, which can be related to disease activity $(40,41)$, and patients may have had more rapidly progressive cancer, in which PD-1 inhibitors are less effective (42). Besides, the incidence of irAEs of any grade was low in frail patients, especially in the younger group. Although, we speculate that this was influenced by the shorter treatment duration. It is noteworthy that $33.3 \%$ of elderly patients with high frailty were able to continue PD-1/PD-L1 inhibitor treatment for $>6$ months. We consider this data valuable because these patients may have no indication of conventional chemotherapy, and PD-1/PD-L1 inhibitors may provide an opportunity to prolong life expectancy with safety and mild toxicity. This data may become more meaningful when PD-1/PD-L1 inhibitor treatment indication has expanded more broadly, and we hope this result serves as a basis for future research.

There are several limitations in this study. First, this was a single-center retrospective study. Therefore, the analyzed data were limited by its retrospective nature, and the patient sample size was relatively small. However, the collected data were purely based on daily clinical practice in our hospital and we did not include patients on clinical trials because these patients could have closer monitoring of adverse events; thus, we believe that our cohort was representative of the general population. Second, we used indirect markers for the evaluation of frailty instead of formal geriatric assessment, because it was not performed in our study cohort. Indeed, geriatric assessment will help us clearly identify vulnerable and frail patients. Nevertheless, our three-element frailty scoring system showed more frail patients in the elderly patients indicating that this method was reasonable.

Therefore, based on data of the 'real-world' population, we demonstrated that mild and severe irAEs developed similarly in non-elderly and elderly patients treated with PD-1/PD-L1 inhibitors. In elderly patients, frailty evaluation seemed to be essential in the safe management of PD-1/PD-L1 inhibitor treatment. Simultaneously, we also note that a certain proportion of frail elderly patients can receive great benefit from these drugs with close monitoring. Therefore, further prospective studies are required to evaluate the safety of ICI treatment in frail patients using geriatric assessment and identify predictive biomarkers for optimizing the application of antitumor immunotherapy.

\section{Acknowledgements}

Not applicable.

\section{Funding}

No funding was received.

\section{Availability of data and materials}

The datasets used and/or analyzed during the current study are available from the corresponding author on reasonable request.

\section{Authors' contributions}

TS, TI and YI were responsible for the design of the study, selection and analysis and interpretation of the data. They also have revised critically the manuscript for important intellectual content. TI, JU, YT, SK, JA, AA, HT, TK, HK, FH, MI, $\mathrm{SH}, \mathrm{OU}, \mathrm{TT}$ and $\mathrm{KT}$ were responsible for the acquisition and clinical interpretation of the data. All authors had full access to all of the data in the study and had final responsibility for the decision to submit for publication. All authors read and approved the final manuscript.

\section{Ethics approval and consent to participate}

The present study was designed under the responsibility of Kyoto Prefectural University of Medicine, in conjunction with the steering committee (approval no. ERB-C-867-1). Given the retrospective nature of this work, the requirement for informed consent was waived for the individual participants included in the study in accordance with the standards of the Kyoto Prefectural University of Medicine Institutional Medical Ethics Review Committee.

\section{Patient consent for publication}

Not applicable.

\section{Competing interests}

YI has received research grants and lecture fees from Ono Pharmaceutical Co., Ltd., Bristol-Myers Squibb, MSD and research grants from Chugai Pharmaceutical Co., Ltd. TI and TT received lecture fees from Ono Pharmaceutical Co., Ltd. and Chugai Pharmaceutical Co., Ltd. TT has also received research grants from Chugai Pharmaceutical Co., Ltd. KT and OU have received research grants from Ono Pharmaceutical Co., Ltd. and Chugai Pharmaceutical Co., Ltd. KT has also received lecture fees from Ono Pharmaceutical Co., Ltd., Bristol-Myers Squibb, MSD and Chugai Pharmaceutical Co., Ltd. The authors declare that all these conflicts of interest are not connected with the issue of this paper. The other authors have no conflicts of interest to declare.

\section{References}

1. National Cancer Institute: Cancer Stat Facts: Cancer of Any Site. Available from: https://seer.cancer.gov/statfacts/html/all.html. Accessed December 16, 2019.

2. Wildiers H, Heeren P, Puts M, Topinkova E, Janssen-Heijnen ML, Extermann M,Falandry C,Artz A,BrainE,Colloca G, et al:International Society of Geriatric Oncology consensus on geriatric assessment in older patients with cancer. J Clin Oncol 32: 2595-2603, 2014.

3. Hurria A, Togawa K, Mohile SG, Owusu C, Klepin HD, Gross CP, Lichtman SM, Gajra A, Bhatia S, Katheria V, et al: Predicting chemotherapy toxicity in older adults with cancer: A prospective multicenter study. J Clin Oncol 29: 3457-3465, 2011.

4. Robert C, Long GV, Brady B, Dutriaux C, Maio M, Mortier L, Hassel JC, Rutkowski P, McNeil C, Kalinka-Warzocha E, et al: Nivolumab in previously untreated melanoma without BRAF mutation. N Engl J Med 372: 320-330, 2015.

5. Borghaei H, Paz-Ares L, Horn L, Spigel DR, Steins M, Ready NE, Chow LQ, Vokes EE, Felip E, Holgado E, et al: Nivolumab versus docetaxel in advanced nonsquamous non-small-cell lung cancer. N Engl J Med 373: 1627-1639, 2015. 
6. Motzer RJ, Escudier B, McDermott DF, George S, Hammers HJ, Srinivas S, Tykodi SS, Sosman JA, Procopio G, Plimack ER, et al; CheckMate 025 Investigators: Nivolumab versus everolimus in advanced renal-cell carcinoma. N Engl J Med 373: 1803-1813, 2015.

7. Ferris RL, Blumenschein G Jr, Fayette J, Guigay J, Colevas AD, Licitra L, Harrington K, Kasper S, Vokes EE, Even C, et al: Nivolumab for recurrent squamous-cell carcinoma of the head and neck. N Engl J Med 375: 1856-1867, 2016.

8. Ansell SM, Lesokhin AM, Borrello I, Halwani A, Scott EC, Gutierrez M, Schuster SJ, Millenson MM, Cattry D, Freeman GJ, et al: PD-1 blockade with nivolumab in relapsed or refractory Hodgkin's lymphoma. N Engl J Med 372: 311-319, 2015.

9. Kang Y-K, Boku N, Satoh T, Ryu M-H, Chao Y, Kato K, Chung HC, Chen JS, Muro K, Kang WK, et al: Nivolumab in patients with advanced gastric or gastro-oesophageal junction cancer refractory to, or intolerant of, at least two previous chemotherapy regimens (ONO-4538-12, ATTRACTION-2) A randomised, double-blind, placebo-controlled, phase 3 trial Lancet 390: 2461-2471, 2017.

10. Garon EB, Rizvi NA, Hui R, Leighl N, Balmanoukian AS, Eder JP, Patnaik A, Aggarwal C, Gubens M, Horn L, et al; KEYNOTE-001 Investigators: Pembrolizumab for the treatment of non-small-cell lung cancer. N Engl J Med 372: 2018-2028, 2015.

11. Elias R, Morales J, Rehman Y and Khurshid H: Immune checkpoint inhibitors in older adults. Curr Oncol Rep 18: 47, 2016.

12. Elias R, Karantanos T, Sira E and Hartshorn KL: Immunotherapy comes of age: Immune aging \& checkpoint inhibitors. J Geriatr Oncol 8: 229-235, 2017.

13. Tomihara K, Curiel TJ and Zhang B: Optimization of immunotherapy in elderly cancer patients. Crit Rev Oncog 18: 573-583, 2013.

14. Czesnikiewicz-Guzik M, Lee WW, Cui D, Hiruma Y, Lamar DL Yang ZZ, Ouslander JG, Weyand CM and Goronzy JJ: T cell subset-specific susceptibility to aging. Clin Immunol 127: 107-118, 2008

15. Weng NP, Akbar AN and Goronzy J: CD28(-) T cells: Their role in the age-associated decline of immune function. Trends Immunol 30: 306-312, 2009

16. Filaci G, Fravega M, Negrini S, Procopio F, Fenoglio D, Rizzi M, Brenci S, Contini P, Olive D, Ghio M, et al: Nonantigen specific $\mathrm{CD} 8^{+} \mathrm{T}$ suppressor lymphocytes originate from $\mathrm{CD} 8^{+} \mathrm{CD} 28$ $\mathrm{T}$ cells and inhibit both T-cell proliferation and CTL function. Hum Immunol 65: 142-156, 2004

17. Loh KP, Wong ML and Maggiore R: From clinical trials to real-world practice: Immune checkpoint inhibitors in older adults. J Geriatr Oncol 10: 384-388, 2019.

18. Oken MM, Creech RH, Tormey DC, Horton J, Davis TE, McFadden ET and Carbone PP: Toxicity and response criteria of the Eastern Cooperative Oncology Group. Am J Clin Oncol 5: 649-655, 1982

19. Charlson ME, Pompei P, Ales KL and MacKenzie CR: A new method of classifying prognostic comorbidity in longitudinal studies: Development and validation. J Chronic Dis 40: 373-383, 1987.

20. Nishijima TF, Deal AM, Williams GR, Guerard EJ, Nyrop KA and Muss HB: Frailty and inflammatory markers in older adults with cancer. Aging (Albany NY) 9: 650-664, 2017.

21. Sato Y, Gonda K, Harada M, Tanisaka Y, Arai S, Mashimo Y, Iwano H, Sato H, Ryozawa S, Takahashi T, et al: Increased neutrophil-to-lymphocyte ratio is a novel marker for nutrition, inflammation and chemotherapy outcome in patients with locally advanced and metastatic esophageal squamous cell carcinoma. Biomed Rep 7: 79-84, 2017

22. Mirili C, Yilmaz A, Demirkan S, Bilici M and Basol Tekin S Clinical significance of prognostic nutritional index (PNI) in malignant melanoma. Int J Clin Oncol 24: 1301-1310, 2019.

23. Zhang W, Ye B, Liang W and Ren Y: Preoperative prognostic nutritional index is a powerful predictor of prognosis in patients with stage III ovarian cancer. Sci Rep 7: 9548, 2017.

24. Li D, Yuan X, Liu J, Li C and Li W: Prognostic value of prognostic nutritional index in lung cancer: A meta-analysis. J Thorac Dis 10: 5298-5307, 2018.

25. Onodera T, Goseki N and Kosaki G: Prognostic nutritional index in gastrointestinal surgery of malnourished cancer patients. Nihon Geka Gakkai Zasshi 85: 1001-1005, 1984 (In Japanese).
26. Singh H, Kim G, Maher VE, Beaver JA, Pai-Scherf LH and Balasubramaniam S: FDA subset analysis of the safety of nivolumab in elderly patients with advanced cancers. J Clin Oncol 34 (Suppl 15): 10010, 2016.

27. Nosaki K, Saka H, Hosomi Y, Baas P, de Castro G Jr, Reck M, Wu YL, Brahmer JR, Felip E, Sawada T, et al: Safety and efficacy of pembrolizumab monotherapy in elderly patients with PD-L1-positive advanced non-small-cell lung cancer: Pooled analysis from the KEYNOTE-010, KEYNOTE-024, and KEYNOTE-042 studies. Lung Cancer 135: 188-195, 2019.

28. Spigel D, Schwartzberg L, Waterhouse D, Chandler J, Hussein M, Jotte R, Stepanski E, Mccleod M, Page R, Sen R, et al: Is nivolumab safe and effective in elderly and PS2 patients with non-small cell lung cancer (NSCLC)? Results of CheckMate 153. J Thorac Oncol 12: S1287-S1288, 2017.

29. Sattar J, Kartolo A, Hopman WM, Lakoff JM and Baetz T: The efficacy and toxicity of immune checkpoint inhibitors in a real-world older patient population. J Geriatr Oncol 10: 411-414, 2019

30. Leroy V, Gerard E, Dutriaux C, Prey S, Gey A, Mertens C, Beylot-Barry M and Pham-Ledard A: Adverse events need for hospitalization and systemic immunosuppression in very elderly patients (over 80 years) treated with ipilimumab for metastatic melanoma. Cancer Immunol Immunother 68: 545-551, 2019.

31. Muchnik E, Loh KP, Strawderman M, Magnuson A, Mohile SG, Estrah V and Maggiore RJ: Immune checkpoint inhibitors in real-world treatment of older adults with non-small cell lung cancer. J Am Geriatr Soc 67: 905-912, 2019.

32. Handforth C, Clegg A, Young C, Simpkins S, Seymour MT, Selby PJ and Young J: The prevalence and outcomes of frailty in older cancer patients: A systematic review. Ann Oncol 26: 1091-1101, 2015.

33. Welaya K, Loh KP, Messing S, Szuba E, Magnuson A, Mohile SG and Maggiore RJ: Geriatric assessment and treatment outcomes in older adults with cancer receiving immune checkpoint inhibitors. J Geriatr Oncol 11: 523-528, 2020.

34. Archibald WJ, Victor AI, Strawderman MS and Maggiore RJ: Immune checkpoint inhibitors in older adults with melanoma or cutaneous malignancies: The Wilmot Cancer Institute experience. J Geriatr Oncol 11: 496-502, 2020.

35. Gleason LJ, Benton EA, Alvarez-Nebreda ML, Weaver MJ, Harris MB and Javedan H: FRAIL questionnaire screening tool and short-term outcomes in geriatric fracture patients. J Am Med Dir Assoc 18: 1082-1086, 2017.

36. Facon T, Dimopoulos MA, Meuleman N, Belch A, Mohty M, Chen WM, Kim K,ZamagniE, Rodriguez-Otero P,Renwick W, et al: A simplified frailty scale predicts outcomes in transplant-ineligible patients with newly diagnosed multiple myeloma treated in the FIRST (MM-020) trial. Leukemia 34: 224-233, 2020.

37. Santini FC, Rizvi H, Plodkowski AJ, Ni A, Lacouture ME, Gambarin-Gelwan M, Wilkins O, Panora E, Halpenny DF, Long NM, et al: Safety and efficacy of re-treating with immunotherapy after immune-related adverse events in patients with NSCLC. Cancer Immunol Res 6: 1093-1099, 2018.

38. Simonaggio A, Michot JM, Voisin AL, Le Pavec J, Collins M, Lallart A, Cengizalp G, Vozy A, Laparra A, Varga A, et al: Evaluation of readministration of immune checkpoint inhibitors after immune-related adverse events in patients with cancer. JAMA Oncol 5: 1310, 2019.

39. Dolladille C, Ederhy S, Sassier M, Cautela J, Thuny F, Cohen AA, Fedrizzi S, Chrétien B, Da-Silva A, Plane AF, et al: Immune checkpoint inhibitor rechallenge after immune-related adverse events in patients with cancer. JAMA Oncol 6: 865, 2020.

40. Bowen RC, Little NAB, Harmer JR, Ma J, Mirabelli LG, Roller KD, Breivik AM, Signor E, Miller AB and Khong HT: Neutrophil-to-lymphocyte ratio as prognostic indicator in gastrointestinal cancers: A systematic review and meta-analysis. Oncotarget 8: 32171-32189, 2017.

41. Templeton AJ, McNamara MG, Šeruga B, Vera-Badillo FE, Aneja P, Ocaña A, Leibowitz-Amit R, Sonpavde G, Knox JJ, Tran B, et al: Prognostic role of neutrophil-to-lymphocyte ratio in solid tumors: A systematic review and meta-analysis. J Natl Cancer Inst 106: dju124, 2014.

42. KatoK,MasuishiT,FushikiK,NakanoS,KawakamiT,Kawamoto Y, Narita Y, Tsushima T, Nakatsumi H, Kadowaki S, et al: Impact of tumor growth rate during preceding treatment on tumor response to nivolumab or irinotecan in advanced gastric cancer. J Clin Oncol 37 (Suppl 4): 84, 2019.

This work is licensed under a Creative Commons Attribution-NonCommercial-NoDerivatives 4.0 International (CC BY-NC-ND 4.0) License. 